\title{
Spatial and Temporal Variability of Precipitation Concentration in Iran
}

\author{
Sohrab GhaediA , Ali Shojaian ${ }^{\mathrm{A}}$ \\ Received: July 03, 2020 | Revised: September 13, 2020 | Accepted: October 13, 2020 \\ doi: 10.5937/gp24-27361
}

\begin{abstract}
Precipitation concentration is an important factor to assess climate hazards such as flood and availability of water resources at a regional scale. This paper investigates the spatial and temporal changes of precipitation concentration using the precipitation concentration index (PCI) in 113 stations in Iran for a duration of 30 years $(1988-2017)$. The results show that the mean average of the annual rainfall in Iran varies from $55 \mathrm{~mm}$ in the eastern and central regions (Zabol and Yazd) to $1838 \mathrm{~mm}$ in the southwest coast of the Caspian Sea (Bandar Anzali). The highest coefficient of variation (CV) of precipitation is related to the southeastern and southern parts of the country, whereas the lowest CV is observed in the Caspian Sea coast and northwest region. Therefore, its value is mostly a function of latitude. Precipitation concentration and its $\mathrm{CV}$ are also influenced by topography and reveal more homogeneity in the northern regions. The Mann-Kendall (MK) test on precipitation concentration data indicates that except for 6 stations (ascending in 2 stations and descending in 4stations), there was no significant trend in others. The stations with non-significant ascending values are located mostly in the eastern, central and western parts of the country while the non-significant descending ones can be seen in the central and northeastern regions. The results of Sen's slope estimator are also similar to the values of the MK test.
\end{abstract}

Keywords: Precipitation concentration; Coefficient of variation; PCI trend; Sen Slope; Iran

\section{Introduction}

Precipitation, as an essential climatic element, determines the availability of water resources, the type and extent of agriculture, and the natural physical phenomena (droughts, floods, water stress, plant and animal life, soil erosion, and dust, to name only a few examples) (González-Hidalgo et al., 2011). The amount, time, intensity and frequency of precipitation are the most important factors which indicate the extent of climate change in any precipitation study for any region (Xiao et al., 2018). One consequence of climate change is the increase in the number of climate extreme events and thereby changing the precipitation behavior. Climate change can affect the month- ly and seasonal distribution of precipitation. In arid and semi-arid lands like Iran, the spatial and temporal variations of precipitation are of high importance and affect all aspects of residents' lives and planning (Khalili et al., 2016). The low rainfall and severe fluctuations in daily, seasonal and annual time scales are inherent characteristics of Iran's climate (Raziei, 2018; Ghaedi, 2018). More than 2/3 of Iran's area is arid and semi-arid and precipitation in these regions is highly irregular. The results of the analysis of annual precipitation trend has indicated a significant downward trend during the last 30 years over Iran (Salehi et al., 2020).

\footnotetext{
A Shahid Chamran University of Ahvaz, Literature and Human faculty, Department of geography and urban planning, Khuzestan province, Ahvaz, s.ghaedi@scu.ac.ir; Shojain@scu.ac.ir

* Corresponding author: Sohrab Ghaedi, e-mail: s.ghaedi@scu.ac.ir
} 
Investigating the precipitation structure provides a useful tool to determine the nature of climate phenomena and climate hazards associated with precipitation (Huang et al., 2016; Liu et al., 2016; Yan, 2017; Zubieta et al., 2017; Li et al., 2018; Huang et al., 2019). The analysis of precipitation concentration can provide us with temporal precipitation structure which is an important factor in determining the climate of a region (Zhang et al., 2019). The precipitation concentration determines the temporal distribution of precipitation in a region over a one-year period. Several concepts have been proposed in examining the concentration of precipitation including the daily concentration index (CI) which evaluates days with maximum precipitation against the annual amount (Martin-Vide, 2004), the precipitation concentration period ( $\mathrm{PCP}$ ) which presents the period (month) in which all annual precipitation is concentrated, the precipitation concentration degree (PCD) which shows the degree of rainfall distribution during all months of the year (Li et al., 2011), and the precipitation concentration index (PCI) which indicates the year-to-year variability of precipitation concentration.

Higher values of precipitation concentration in a certain region mean that rain would mostly concentrate in these particular areas within a shorter period of time. Higher precipitation concentration increases the length of the dry season which can reduce soil moisture. By reducing soil moisture, many plants are lost and, as a result, conditions will be ripe for wind erosion and desertification. In agriculture, this can reduce crop yields by reducing soil moisture storage and increasing the number of irrigation periods. In addition, the precipitation concentration can lead to climatic hazards such as droughts or floods (Shi et al., 2014).

Much research has been done on the spatio-temporal variability of precipitation concentration in different regions of the world over the past two decades.
Some of these studies have been conducted by Zamani et al. (2018) in India, Rahman et al. (2019) in Bangladesh, Lu et al. (2019) and Zhang et al. (2019) in China, Velez et al. (2019) in Puerto Rico, Caloiero et al. (2019) in Italy, Sangüesa et al. (2018) and Sarricolea et al. (2019) in Chile, Botai et al. (2018) in South Africa, and Al-Shamarti (2016) in Iraq.

Research shows that the trend of precipitation concentration has been decreasing and this means that precipitation occurs in fewer days and months of the year. A study by Abolverdi et al. (2015) on precipitation concentration in Fars province (southwestern Iran) shows that precipitation concentration was increasing in most of the stations under the study. Khalili et al. (2016) surveyed precipitation concentration in 34 synoptic stations in Iran and found that the PCI has a strong irregularity in the central and southern regions with increasing annual trend in 50 percent of the stations. Khalili et al. (2017) studied the trend of precipitation concentration in Iran in 25 stations over the last half of the century (1961-2010) and observed an increasing trend in 40 percent of them. Also, Alijani et al. (2008) investigated the daily precipitation structure in 90 stations in Iran and found that the highest concentration index was related to the coasts of the Persian Gulf and the Caspian Sea. Amiri and Mesgari (2019) observed irregularities in the temporal distribution of PCI and a decreasing gradient from the southeast to the northwest of Chaharmahal and Bakhtiari province in Iran. Ramezani et al. (2020) investigated the PCI in the Lake Urmia basin and found that it was neither in regular nor in strongly irregular conditions at any of the stations studied.

The first purpose of this paper is to examine the precipitation concentration in Iran. The second objective is to calculate the trend and line slope of the precipitation concentration over a thirty-year period.

\section{Data and Methods}

\section{Study area and data}

Iran is located in the southwest of the Asian continent and except the Khuzestan plain and the Caspian Sea coasts, its other regions are situated on the plateau of Iran. The Alborz and Zagros Mountains are the limits of the plateau in the northern and western strips, respectively. Moreover, there are mountains in the central and eastern parts of the country. The area of Iran is more than $1648000 \mathrm{~km}^{2}$ and lies between $25^{\circ} 3^{\prime}$ and $39^{\circ} 47^{\prime}$ northern latitude and $44^{\circ} 5^{\prime}-63^{\circ} 18^{\prime}$ eastern longitude. The elevation of different regions of Iran varies between $-28 \mathrm{~m}$ (Caspian Sea coasts) to $5670 \mathrm{~m}$ (the peak of Mount Damavand). The variation of elevation, the impact of various air mass systems from different directions, and its extension over a wide latitude range have caused diverse climate in this territory (Ghaedi, 2019).

The present research was carried out using monthly average precipitation data taken from 113 synoptic stations all over the country with data of 30 years (1 Jan 1988- 31 Dec 2017). The meteorological stations practically include all the territory of the climatic and elevation regions in Iran. The distribution of the stations and their elevation is presented in Figure 1. The uneven distribution of the stations under research is due to the existence of mountainous regions and vast deserts in central Iran. 

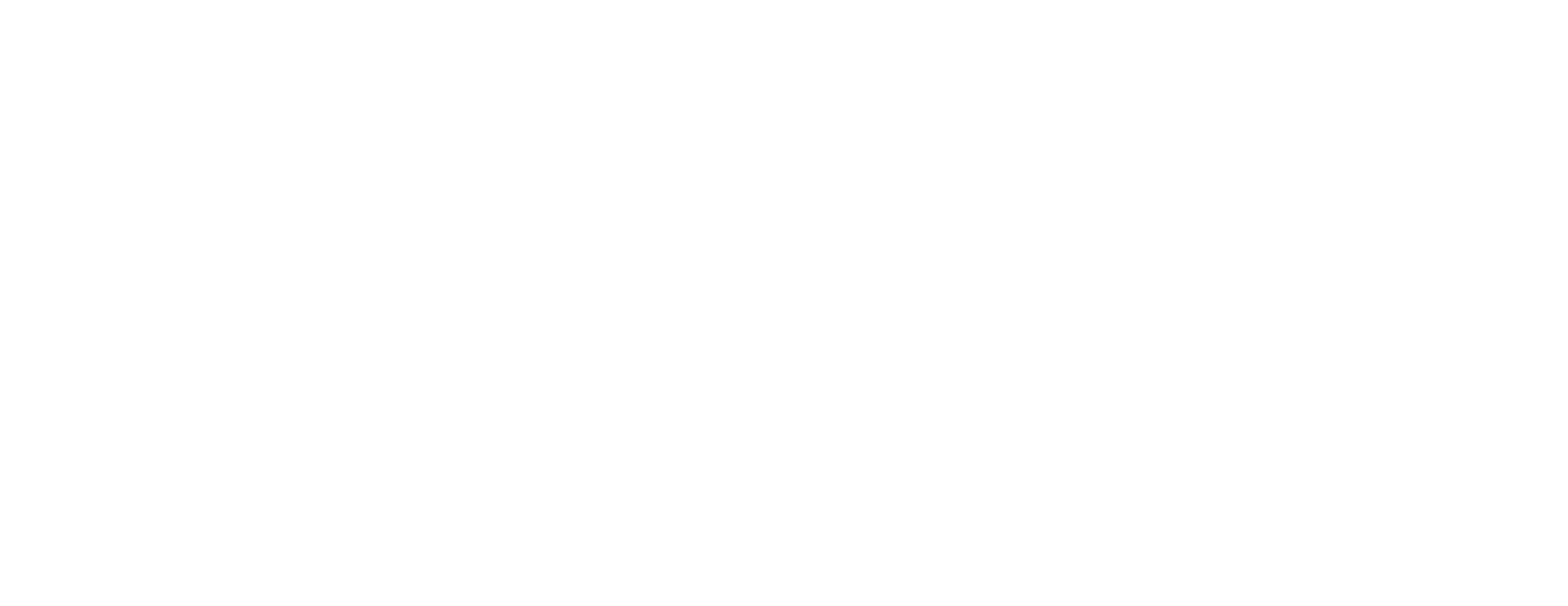

Figure 1. The location (a) and elevation (b) of the stations under the study

\section{Precipitation Concentration Index ( $\mathrm{PCI})$}

Oliver proposed the PCI for the first time in 1980. PCI is used to measure the degree of monthly and seasonal precipitation concentration and can be calculated via the following relation:

$$
\text { PCI }=\frac{\sum_{i=1}^{12} M P_{i}^{2}}{\left(\sum_{i=1}^{12} M P_{i}\right)^{2}} \cdot 100
$$

Where $M P_{i}$ is the monthly precipitation in the $i^{\text {th }}$ month. According to this equation, if the annual rainfall occurs in only one month, the PCI will be the maximum and equal to 100 . The minimum PCI is 8 and will be when the rainfall occurs evenly throughout all the months (Lu et al., 2019).

If PCI is less than 10 , it will be indicative of uniform precipitation distribution (the precipitation has low concentration).

If PCI is between 11 and 15 , that would indicate moderate precipitation concentration.

If PCI is between 16 and 20, it shows irregular distribution and when PCI is more than 20, this may indicate a strong irregularity (the precipitation has high concentration).

\section{Mann Kendall trend test}

The nonparametric Mann-Kendall test (Mann, 1945; Kendall, 1975) was used for the detection of the trend of PCI. One of the advantages of this method is that it does not consider any particular form of data distribution function. Several studies such as those by Trbić et al. (2017) and Ogrin et al. (2018) have employed the method and the details about Mann-Kendall trend test. In the present study, the data series was examined at the significance level of $95 \%$. Commonly, the nonparametric MK trend test is based on the assumption of independence between observations. To remove the effect of possible autocorrelation on the trend test, autocorrelation analysis was initially used to check data randomness and independence on the time series. Therefore, function autocorrelation has been used in the present research (von Storch, 1995).

Zero lag coefficient for independent and random data series is near zero, which means that MK trend can be directly used to test the data series. Otherwise, if the autocorrelation coefficient is equal or more than one, pre-whitening procedure is necessary.

\section{Sen's slope estimator}

The Sen's slope method was applied to estimate the slope of PCI beside the MK trend test (Se, 1968). The Sen's method estimates the slope of the trend by applying a linear model, and the variance of the residuals at the time of calculation should be constant. Based on this method, summary slope is estimated as the median of all pair-wise slopes between each pair of points in the time series (Kumar et al., 2017).

\section{Discussion and Results}

\section{Mean annual precipitation}

The mean annual precipitation of Iran during the study period is presented in Figure 2. The amount of annual precipitation varies from $55 \mathrm{~mm}$ in the central and eastern regions to $1838 \mathrm{~mm}$ in the Caspian Sea coast. The two maximum rainfall belts are seen first on the Caspian Sea coastlines and then on the Zagros Mountains. In a framework between latitude $25^{\circ}$ and $35^{\circ} \mathrm{N}$ and longitude $54^{\circ}$ and $64^{\circ} \mathrm{E}$, the amount of precipitation is less than $200 \mathrm{~mm}$ (including the Dasht-e Kavir and Dasht-e 
Lut deserts and except for a small area south of Kerman including Lalehzar mountain). Minimum rainfalls occur due to low elevation and being far from moisture sources in the central and eastern regions. Topography (the elevation of the vast land of Iran with $1648195 \mathrm{~km}^{2}$ area varies between -28 and 5671 meters), latitude $\left(25^{\circ}\right.$ and $40^{\circ} \mathrm{N}$ ) and distance from the Caspian Sea (the largest lake on earth and an important humidity source in the north of Iran) are the essential factors impacting the spatial distribution of precipitation in Iran.

Although the Persian Gulf and the Oman Sea as two moisture sources are available in the southern parts of

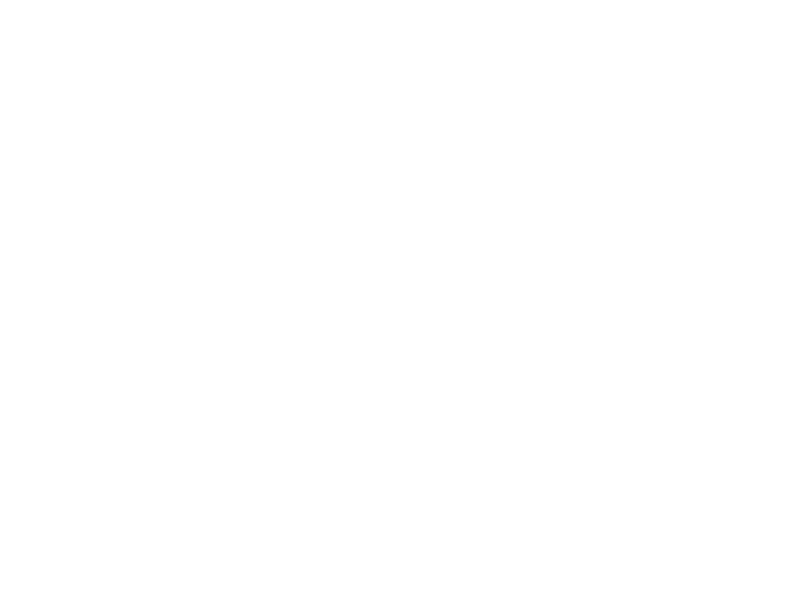

Figure 2. Spatial distribution of mean annual precipitation $(\mathrm{mm})$ across Iran over the period 1988-2017

the country, precipitation is very low. Because of their low latitude, the Mediterranean Sea and the Red Sea rainfall systems have been operating in these regions during part of the year. On the other hand, the altitude of these areas is low and the subtropical high pressure has been established for a long time. Arabian subtropical high pressure, which is the tongue of the Azores subtropical high pressure, is located over Iran from May to October and does not allow the arrival of precipitation systems, except in limited cases (Lashkari \& Mohammadi, 2019). Mediterranean cyclones and the Red Sea trough cause rainfalls during the cold periods of the year (October to November) in all southern regions of Iran and Gang low pressure causes rainfalls during the warm periods of the year (June to September) more in the southeastern regions of Iran.

\section{Coefficient of variation (CV) of annual precipitation}

Figure 3 illustrates the results of spatial variation for the $\mathrm{CV}$ of annual precipitation in the study region. According to this map, the $\mathrm{CV}$ for the stations ranged from 15.3 to 83.2 percent per year. The highest CV $(83.2 \%)$ is related to Chahbahar station with a mean annual rainfall of about $112 \mathrm{~mm}$ per year, whereas the lowest CV (15.3\%) is observed in Nushahr station with the mean annual precipitation value of $1295 \mathrm{~mm}$ per year. Therefore, it can be concluded that the $\mathrm{CV}$ of precipitation in humid and mountainous regions is less than that in the dry regions.

Much in the same way as precipitation, the CV of annual precipitation is also a function of latitude and topography. Regardless of the changes resulting from the elevation factor, $\mathrm{CV}$ of precipitation increases as we move from northwest to southeast. The mountainous regions including the Alborz mountains, the $\mathrm{Za}$ gros mountains and the Central zone partially decrease the $\mathrm{CV}$ of precipitation because the orographic

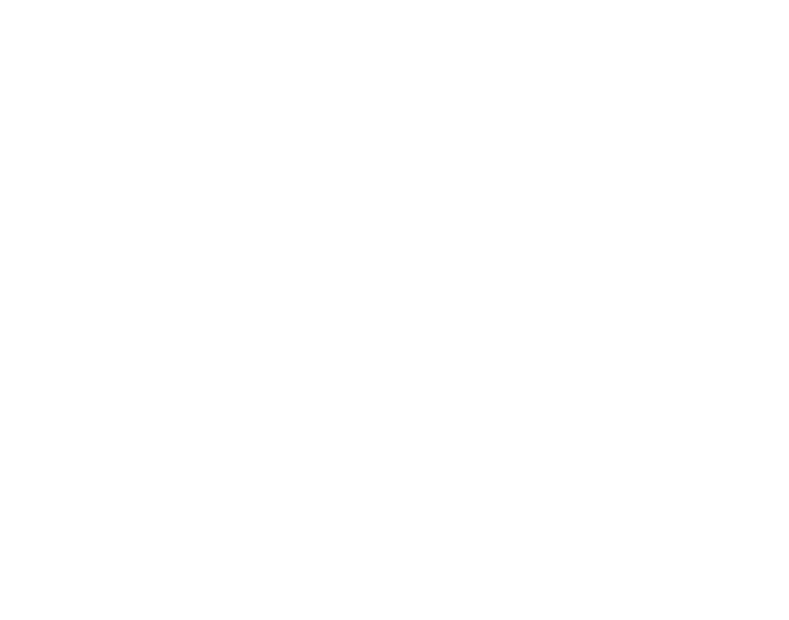

Figure 3. CV of annual precipitation across Iran over the period 1988-2017

ascent of air masses is one of the important factors in creating precipitation in Iran.

\section{Spatial distribution of $\mathrm{PCl}$}

The spatial analysis of PCI indicates that precipitation has not occurred uniformly (less than 10) in any station. In general, the PCI values increase by moving from north to south and west to east. The lowest PCI values has to do with the regions distributed along the southern coast of the Caspian Sea and the regions with high elevation in northwestern Iran. In these regions, the annual precipitation is relatively distributed evenly throughout the year and the dry season is relatively short. In the mountainous regions of western, northern and northwestern Iran, the PCI values range from 15 to 30 . This indicates that these stations are featured with a pronounced seasonality, and so they have a long dry season for half of the year. The PCI considerably increases eastward and southward to the low elevation regions and deserts of southern and central Iran. The highest PCI values (more than 30) are featured all among the regions located in southern and especially southeastern Iran, which itself shows that the total annual precipitation in this part of the country is extremely concentrated in less than a few months of the 


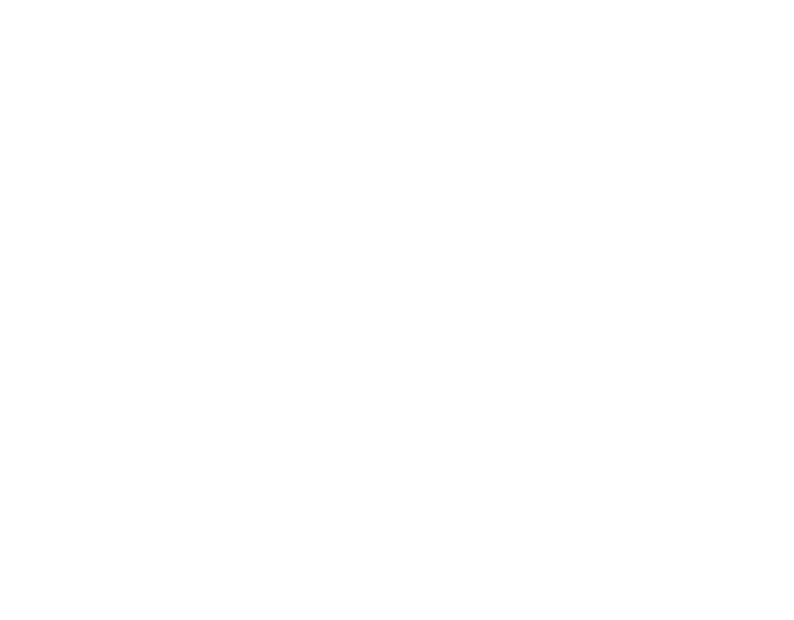

Figure 4. Spatial distributions of $\mathrm{PCl}$ across Iran over the period 1988-2017

year. Therefore, in terms of latitude, the precipitation concentration decreases from south to north. The second factor that affects the spatial distributions of PCI is topography and hence it has led to a decrease in the precipitation concentration in the Zagros and Alborz mountains. This shows that orographic ascent plays an important role in rainfalls across Iran.

\section{Coefficient of variation (CV) of $\mathrm{PCl}$}

The CV of PCI (Figure 5) has a relatively similar spatial distribution to the PCI (Figure 4). While the lowest values are observed in the southeastern coast of the Caspian Sea and in the northwest of the country, the highest values are seen in the southeastern parts (Sistan and Baluchestan province). The second highest center is related to the islands and the eastern coasts of the Persian Gulf. Therefore, two northwest-southeast and north-south gradients can be seen in spatial patterns. The role of the Zagros and Alborz elevations in decreasing the coefficient of variation is clearly visible. However, at a limited number of stations in the

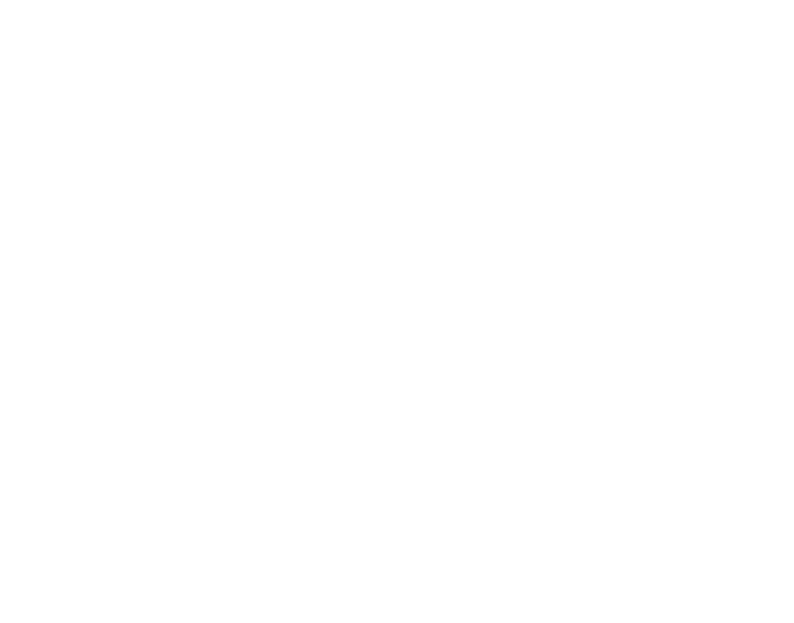

Figure 6. Results of the Mann-Kendall trend test across Iran over the period 1988-2017

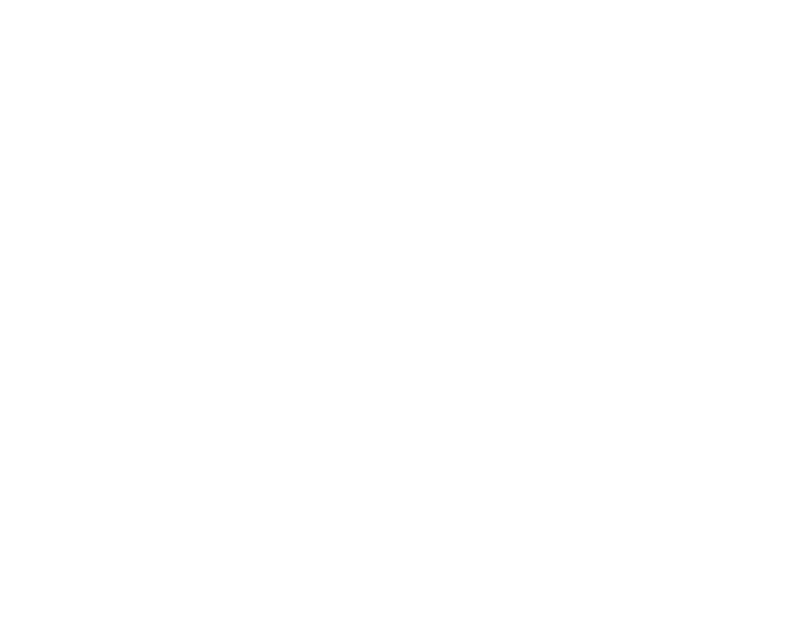

Figure 5. The coefficients of variation (CV) of $\mathrm{PCl}$ across Iran over the period 1988-2017

northwest region and southwestern coast of the Caspian Sea, the variability is higher than that in the surrounding area, which indicates variability in the arrival time of precipitation systems.

\section{Mann Kendall trends analysis of $\mathrm{PCl}$}

The results of Mann Kendall trend test in 95\% significance level are presented in Figure 6. Generally, regions with negative trends have been detected in the entire Central and northeastern parts of the country (in about $43 \%$ of the stations). Around $51 \%$ of the stations show a non-significant upward trend, mostly located in the southeast, central and western parts of the country. The positive trend of precipitation concentration in the western and southeastern regions indicates that in these regions the period of the activity of precipitation systems has decreased.

\section{Sen's slope estimator of $\mathrm{PCI}$}

Figure 7 shows the spatial distribution of Sen's slope for the studied period. The positive and negative Sen's

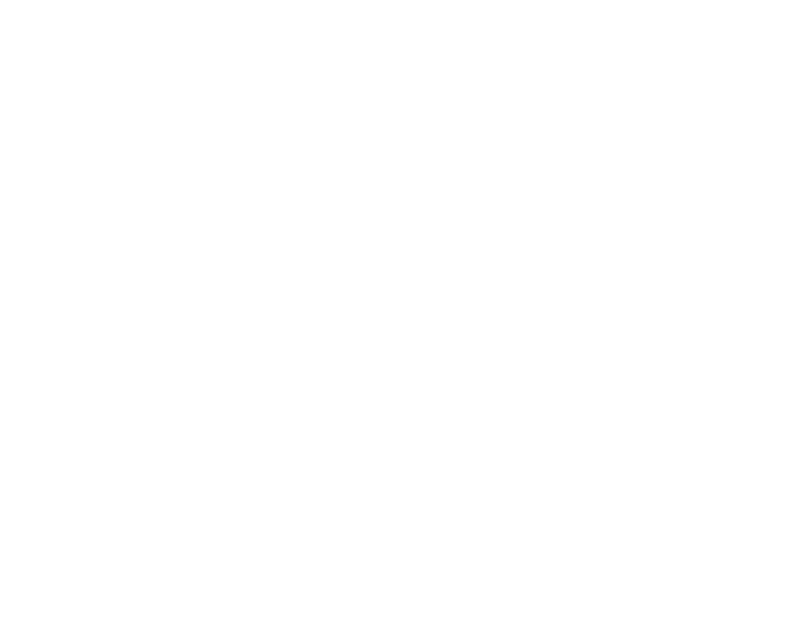

Figure 7. Spatial distribution of Sen's slope test across Iran over the period 1988-2017 
slopes are very similar to the results of Mann Kendall trends. The findings of Sen's slope illustrate positive slopes in the western, southeastern and central regions. Among the regions with positive slope, from south to north and toward the northeast of the country, stations begin to have negative slopes. The values of Sen's slope vary from 0.87 in the southeastern part of the country to -0.54 in Siri and Kish islands in the Persian Gulf. Overall, a positive slope of precipitation concentration was observable in 52 percent of the territory under study.

\section{Conclusion}

The spatial variability of annual precipitation was in vestigated in Iran using rainfall data of 113 stations between 1988 and 2017. There is a lot of heterogeneity in Iran in terms of rainfall distribution, coefficient of variation, precipitation concentration and trends. Latitude, topography and distance from the Caspian Sea are the major factors in explaining the spatial distribution of these variations. The spatial distribution of mean annual precipitation illustrated that Iran's precipitation is a function of these factors. The lowest amount of rainfall occurs in the central and eastern parts while the highest annual precipitation occurs in the southwestern coast of the Caspian Sea. Thus, the distance from the Caspian Sea has a major impact on the amount of precipitation and its surrounding areas.

In terms of the $\mathrm{CV}$ of annual precipitation, the highest value $(83.2 \%)$ is related to the southeastern region (Chahbahar station) whereas the lowest CV (15.3\%) is observed in Nushahr station.

The maximum precipitation concentration values in Iran are mainly seen in the southeastern region. From this area to the north and northwest, the precipitation concentration gradually decreases. Precipitation concentration values of less than 20 (moderate and irregular distribution) are only observed at latitudes above $35^{\circ} \mathrm{N}$; although the Zagros altitudes in the west of the country have slightly moderated the values to $32^{\circ} \mathrm{N}$. Based on the PCI spatial distribution, the northern belt of Iran has a precipitation regime with a moderate seasonality, i.e., a very short dry season, while a defined precipitation seasonality with a longer dry season characterizes the mountainous regions of western and northern Iran. The most sea- sonal precipitation regime with the longest dry season is related to southern and especially southeastern Iran. Moreover, the spatial pattern of the dry period throughout Iran has a longitude gradient, although the topography disorders this pattern in the western and northeastern regions of the country.

The highest values of the CV of PCI were observed in southeastern and southern regions of Iran. The amount of the CV of PCI gradually increases from these regions toward northwestern and northern areas.

The study of the trends of precipitation concentration in the studied stations over a thirty-year period revealed that in 51 percent of stations the trends are non-significantly increasing at the significance level of $95 \%$. It is significantly increasing in 2 percent of them which are mostly located in the southeast, central and western parts. However, in the central regions from the northern to the southern and northeastern parts, most of the stations have a decreasing trend (44\% non-significant and 3\% significant).

The results of Sen's slope estimator test indicated an increasing slope in the western, southeastern and central regions of the country (52\%) and a decreasing trend in other regions (48\%).

In addition to the decreasing trend of precipitation in Iran, the temperature trend in Iran is positive (Ahmadi et al., 2018) and this could mean the climate change has occurred in Iran. The findings of this research and those of other researches regarding the trend of climate variables can be used in water resource management, to reduce the risk of drought and floods, environmental conservation, and preparedness for disasters.

\section{References}

Abolverdi, J., Ferdosifar, G., Khalili, D., \& Kamgar-Haghighi, A. A., (2016). Spatial and temporal changes of precipitation concentration in Fars province, southwestern Iran. Meteorology and Atmospheric Physics, 128(2), 181-196.

Ahmadi, F., Nazeri Tahroudi, M., Mirabbasi, R., Khalili, K., \& Jhajharia, D. (2018). Spatiotemporal trend and abrupt change analysis of temperature in Iran. Meteorological Applications, 25(2), 314-321.

Alijani, B., O’Brien, J., \& Yarnal, B., (2008). Spatial analysis of precipitation intensity and concentration in Iran. Theoretical and Applied Climatology 94, 107-124. 
Al-Shamarti, H.K., (2016). The variation of annual precipitation and precipitation concentration index of Iraq. Journal of Applied Physics, 8(4), 36-44.

Amiri, M.A., \& Mesgari, M.S., (2019). Spatial variability analysis of precipitation and its concentration in Chaharmahal and Bakhtiari province, Iran. Theoretical and Applied Climatology 137(3-4), 2905-2914.

Botai, C.M., Botai, J.O., \& Adeola, A.M., (2018). Spatial distribution of temporal precipitation contrasts in South Africa. South African Journal of Science, 114(7-8). 70-78

Caloiero, T., Coscarelli, R., Gaudio, R., \& Leonardo, G.P., (2019). Precipitation trend and concentration in the Sardinia region. Theoretical and Applied Climatology 137(1-2), 297-307,

Ghaedi, S., (2018). Atmospheric circulation patterns of heavy precipitation in warm season in Iran. MAUSAM 69(1), 115-122.

Ghaedi, S., (2019). The variability and trends of monthly maximum wind speed over Iran. IDOJARAS 123(4), 521-534.

González-Hidalgo, J.C., Brunetti, M., \& De Luis, M., (2011). A new tool for monthly precipitation analysis in Spain. MOPREDAS database (monthly precipitation trends December 1945-November 2005). International Journal of Climatology 31(5), 715-731.

Huang, S., Huang, Q., Chen, Y., Xing, L., \& Leng, G., (2016). Spatial-temporal variation of precipitation concentration and structure in the Wei River Basin, China. Theoretical and applied climatology 125(1-2), 67-77.

Huangm Y., Wang, H., Xiao, W.H., Chen, L.H., \& Yang, H., (2019). Spatiotemporal characteristics of precipitation concentration and the possible links of precipitation to monsoons in China from 1960 to 2015. Theoretical and Applied Climatology 138(12), 135-152.

Kendall, M.G. (1975). Rank Correlation Methods Charles, London, Charles Griffin press.

Khalili, K., Tahoudi, M.N., Mirabbasi, R., \& Ahmadi, F., (2016). Investigation of spatial and temporal variability of precipitation in Iran over the last half century Stochastic environmental. Research and risk assessment 30(4), 1205-1221.

Khalili, K., Tahrudi, M.N., Moghaddamnia, A.R., Moravej, M., \& Afshar, M.A., (2017). Investigation of PCI Drought Index and Its Trend over Iran in the recent half century. Journal of Irrigation Sciences and Engineering 37(3), 195-207. (In Persian with English summary)

Kumar, N., Panchal, C.C., Chandrawanshi, S.K., \& Thanki, J.D., (2017). Analysis of rainfall by using Mann-Kendall trend, Sen's slope and variability at five districts of south Gujarat, India. Mausam 68(2), 205-222.
Lashkari, H., \& Mohammadi, Z. (2019). Study on the role of annual movements of Arabian subtropical high pressure in the late start of precipitation in southern and southwestern Iran. Theoretical and Applied Climatology, 137(3-4), 2069-2076.

Li, X., Jiang, F., Li, L., \& Wang, G., (2011). Spatial and temporal variability of precipitation concentration index, concentration degree and concentration period in Xinjiang, China. International Journal of Climatology 31(11), 1679-1693.

Li, X., Janiga, M.A., Wang, S., Tao, W.K., Rowe, A., Xu, W., \& Zhang, C., (2018). Evolution of precipitation structure during the November DYNAMO MJO Event. Cloud-Resolving Model Inter comparison and Cross Validation Using Radar Observations. Journal of Geophysical Research. Atmospheres 123(7), 3530-3555.

Liu, B., Li, Y., Chen, J., \& Chen, X., (2016). Long-term change in precipitation structure over the karst area of Southwest China. International Journal of Climatology 36(6). 2417-2434

Lu, Y., Jiang, S., Ren, L., Zhang, L., Wang, M., Liu, R., \& Wei, L., (2019). Spatial and temporal variability in precipitation concentration over mainland China, 1961-2017. Water 11(5), 881.

Mann, H.B., (1945). Non-parametric test against trend. Econometrica 13, 245-259.

Martin-Vide, J. (2004). Spatial distribution of a daily precipitation concentration index in Peninsular Spain. International Journal of Climatology 24, 959-971.

Ogrin, M., Nikolić, G., Ogrin, D., \& Trobec, T. (2018). An investigation of winter minimum temperatures in the mountains of Montenegro: A case study from the karst depression of Valoviti Do and selected mountain stations of northern Montenegro. Geographica Pannonica, 22(4), 241-252.

Rahman, M.S., \& Islam, A.R.M.T., (2019). Are precipitation concentration and intensity changing in Bangladesh overtimes? Analysis of the possible causes of changes in precipitation systems. Science of the Total Environment (690), 370-387.

Ramezani, Y., Khashei-Siuki, A., \& Tahroudi, M. N., (2020). Spatial distribution of the daily, monthly, and annual precipitation concentration indices in the Lake Urmia basin, Iran. IDOJARAS, 124(1), 7395.

Raziei, T., (2018). An analysis of daily and monthly precipitation seasonality and regimes in Iran and the associated changes in 1951-2014. Theoretical and applied climatology 134(3-4), 913-934.

Sangüesa, C., Pizarro, R., Ibañez, A., Pino, J., Rivera, D., García-Chevesich, P., \& Ingram, B., (2018). Spatial and temporal analysis of rainfall concentration using the Gini index and PCI. Water 10(2), 112. 
Salehi, S., Dehghani, M., Mortazavi, S.M., \& Singh, V.P., (2020). Trend analysis and change point detection of seasonal and annual precipitation in Iran. International Journal of Climatology 40(1), 308-323.

Sarricolea, P., Meseguer-Ruiz, Ó., Serrano-Notivoli, R., Soto, M.V., \& Martin-Vide, J., (2019). Trends of daily precipitation concentration in Central-Southern Chile. Atmospheric Research (215), 85-98.

Sen, P.K., (1968). Estimates of the regression coefficient based on Kendall's tau. J Am Stat Assoc, 63, 1379-1389.

Shi, P., Qiao, X., Chen, X., Zhou, M., Qu, S., Ma, X., \& Zhang, Z., (2014). Spatial distribution and temporal trends in daily and monthly precipitation concentration indices in the upper reaches of the Huai River, China. Stochastic Environmental Research and Risk Assessment, 28(2), 201-212.

Trbić, G., Popov, T., \& Gnjato, S. (2017). Analysis of air temperature trends in Bosnia and Herzegovina. Geographica Pannonica, 21(2), 68-84.

Velez, A., Martin-Vide, J., Royé, D., \& Santaella, O., (2019). Spatial analysis of daily precipitation concentration in Puerto Rico. Theoretical and Applied Climatology 136(3-4), 1347-1355.
Xiao, C., Yuan, W., \& Yu, R., (2018). Diurnal cycle of rainfall in amount, frequency, intensity, duration, and the seasonality over the UK. International Journal of Climatology 38(13), 4967-4978.

Yan, T., \& Bai, Z.S., (2017). Spatial and temporal changes in temperature, precipitation, and streamflow in the Miyun Reservoir Basin of China. Water 9(2), 78-88.

Zamani, R., Mirabbasi, R., Nazeri, M., Meshram, S.G., \& Ahmadi, F., (2018). Spatio-temporal analysis of daily, seasonal and annual precipitation concentration in Jharkhand state, India Stochastic environmental research and risk assessment, 32(4), 10851097.

Zhang, K., Yao, Y., Qian, X., \& Wang, J., (2019). Various characteristics of precipitation concentration index and its cause analysis in China between 1960 and 2016. International Journal of Climatology 39(12), 4648-4658.

Zubieta, R., Saavedra, M., Silva, Y., \& Giráldez, L., (2017). Spatial analysis and temporal trends of daily precipitation concentration in the Mantaro River basin. Central Andes of Peru. Stochastic Environmental Research and Risk Assessment 31(6), 13051318. 